\title{
La estructura Productiva y Formas de Organización en la Artesanía Tonalteca, 2010. Estudio de Caso
}

\author{
THE PRODUCTIVE STRUCTURE END FORMS OF ORGANIZATION IN THE 2010 TONALTECA \\ HANDICRAFTS. CASE STUDY
}

\author{
Rosario Cota Yáñez (*) \\ Carlos Franco Flores ${ }^{(*)}$
}

Resumen: La actividad productiva artesanal en el actual mundo global se ve afectada por los cambios en las necesidades de los consumidores, la competitividad en el sector manufacturero y por la deficiencia en la especialización de los talleres en adecuarse a establecer organizaciones empresariales. Este artículo busca determinar cómo se han modificado los sistemas de producción y el impacto asimétrico con la fabricación artesanal. Centrándose en exponer la situación del entorno comercial de las unidades artesanales y las estrategias que desarrollan para subsistir y ofertar productos en el mercado de artículos decorativos. La metodología consistió en un estudio de caso, por medio de entrevistas semiestructuradas al dueño del taller, además, de observación participante en 2010.

Palabras claves: Actividad artesanal, Tonalá, sistemas de producción, consumidores, entorno comercial, estrategias.

\begin{abstract}
Productive artisan activity in today's interconnected world is affected by changes in consumer needs, competitivity in the manufacturing sector and by the failure of workshops to adapt and form business associations. This paper seeks to determine what modifications have been made to systems of production and to forms of production and commercialization in artisan manufacturing. It is centred on showing the situation in the commercial environment of the artisan units, and the strategies they have developed in order to survive and offer products in the market for decorative articles. The methodology adopted is that of a case study conducted through semi-structured interviews with the owner of the workshop, and participatory observation, in 2010.
\end{abstract}

Key words: artisan activity, Tonalá, production systems, consumers, commercial environment, strategies.

(*) Profesor-investigador de la Universidad de Guadalajara, Doctora en Ciencias Sociales, Departamento de Estudios Regionales DER-INESER, e-mail: <macotaya@cucea.udg.mx>. Miembro del Sistema Nacional de Investigadores. Pertenece al Cuerpo Académico CA-UDG-643 Reestructuración productiva y estudios locales..

$(* *)$ Egresado de la licenciatura en Negocios Internacionales del Centro Universitario de Ciencias Económico Administrativas, e-mail:<carlos.franco86@gmail.com>. recebido em 23.03.12 e aceito em 01.06.12. 


\section{INTRODUCCIÓN}

La Revolución Industrial marca un parteaguas en los procesos de producción. A partir de entonces se deja de producir en pequeños gremios, para modificarse al aumentar la exigencia de los mercados capitalistas, impulsado por el apogeo de la comercialización internacional.

Para analizar el marco teórico se exponen tres perspectivas: 1) empresarial; teoría de recursos y capacidades; 2) entorno nacional: teoría, desarrollo endógeno y nueva geografía económica; y 3) entorno internacional: ventaja competitiva y comercio intraindustrial. Que tienen como finalidad explicar los efectos económicos y sociales que impactan en las unidades artesanales en la economía global.

La artesanía mexicana a partir de los años noventa ha mantenido una disminución de la demanda a la exportación, dicho fenómeno determina el nivel alto de competitividad en el sector decorativo ${ }^{(1)}$, el requerimiento actual de mercado amerita el desarrollo de nuevos planes y gestiones para ingresar y permanecer en la mente del consumidor.

Por lo que el sector artesanal actual se enfrenta a la inmersión en la dinámica capitalista, al dejar atrás la perspectiva cultural y social del artesano, ya que las empresas "artesanales" requieren modificar totalmente sus enfoques locales de producción para subsistir; a su vez, definir lo que implica la competencia de estos productos en los mercados globales (LUGO-MORIN et al., 2008).

Posterior a la exposición de teorías se detalla el estudio de caso de un taller familiar artesanal, sobre las estrategias que ha desarrollado e innovaciones de sus procesos de producción, organizacionales y de comercialización; con el objeto de modificarse y adaptarse al entorno de competitividad.

\section{Historia de la Producción}

La producción artesanal se reemplazó a finales del siglo XVIII, con el inicio de las primeras fábricas, los cambios económicos, tecnológicos y sociales (Revolución Industrial, a partir de 1750-1780), surge la fabricación de las máquinas y la clase obrera. Al realizar una retrospección histórica, las bases de los procesos productivos empresariales tienen sus antecedentes en los colegios romanos, las guildas, los gremios y las corporaciones de oficios. Dichos modelos de corte artesanal eran valorados más por el trabajo realizado que por la productividad. El esquema de producción, formado por el maestro de oficio y aprendiz entra en decadencia con el ingreso del modelo capitalista, el trabajador vende su fuerza de trabajo, el capitalista la aprovecha a cambio de salario (DE BUEN, 1997).

Con el desarrollo en pie de la revolución industrial, los gremios ceden presencia a las empresas, la energía de vapor exige mayor número de trabajadores, esto a su vez

(1) Dentro del sector se encuentran los artículos representativos: artículos de joyería de plata, oro y metales comunes; estatuillas y adornos de cerámica; velas; artículos para servicio de mesa y decorativos de vidrio. 
hace que se modifiquen las jornadas de trabajo, las cuales se incrementan con el empleo de la iluminación (ibid., 25). El taller familiar, que se enfocaba en su oficio de elaborar productos (trabajo doméstico o maquila ${ }^{(2)}$ ) con capital de los comerciantes, confronta los cambios tecnológicos y políticos. La causal de incrementar la producción ante la mayor exigencia de demanda fue originada por el crecimiento del mercado interno, que se incorporó al papel del comercio exterior, que fungen como los factores trascendentales para dar paso a la producción en masa.

La innovación de la máquina de vapor, en conjunto con la fabricación de tejidos, principalmente a base de algodón que empleaban telares mecánicos fueron las primeras fábricas de producción masiva, se incorporó con ello el desarrollo de la siderúrgica, estos sectores económicos requerían resolver un importante problema: la transportación, para hacer llegar los productos a las nuevas ciudades.

La diferencia en los modelos de producción son claves: el de economías de escala requiere de maximizar los recursos, obtener artículos seriados en menor tiempo al disminuir el lapso de los procesos; se diferencia fácilmente de la producción artesanal, debido al bajo volumen de fabricación, la escasez de puntos de venta y el alto empleo de fuerza manual en los procesos del taller tradicional, que difícilmente se adapta a la exigencia de los mercados internacionales de precios diversificados y alto consumo.

En 1903, Frederick Taylor origina un nuevo concepto de emplear la producción, al descomponer el trabajo en tareas individuales. Al sentar las bases de la administración funcional, forma un modelo organizacional empleado por múltiples organizaciones en la actualidad (COWEN y PARKER, 1998). La modificación del trabajo, desde la perspectiva de Taylor aporta un cambio importante en la dinámica de las organizaciones: División del trabajo: la especialización en tareas determinadas (en tiempos, procesos y programas), y; racionalización del trabajo: cargos simples y elementales en función del trabajo manual e intelectual.

Lo anterior, se requiere para definir los cambios históricos en la producción. El modelo artesanal ha cambiado muy poco; este sector ha mantenido escaso engranaje con la modernidad tecnológica, un bajo empleo de maquinaria y capital invertido en la innovación para aumentar los niveles de producción, la resistencia ha sido permanecer en el mercado exclusivo de las múltiples manufacturas por su valor agregado, pero en contraparte, han innovado en la adaptación y la flexibilidad que se requiere para enfrentar la competitividad del modelo de economía de mercado. Cabe decir que las unidades artesanales de Tonalá, no difieren mucho a la organización de producción de los talleres de mediados del siglo XX (Turok, 1988). Y se pudo comprobar con el presente trabajo.

\section{La Teoría Empresarial en las Unidades Artesanales}

La modificación del modelo artesanal se originó con el cambio de ideología de autoconsumo, por la mercantilización, la demanda del mercado ha ocasionado cambios en

(2) Trabajo a domicilio o Maquila: esta forma de producción, el insumo y capital es dado por los comerciantes, se añade la mano de obra y obtención de los productos a precios establecidos, aún se mantiene dicho esquema en la producción artesanal en algunos Estados de la república mexicana. 
la especialización de la producción, los sectores manufactureros han basado gran parte de su desarrollo en las innovaciones, que forman parte estratégica ante la exigencia por captar mercado en las organizaciones actuales. El sector artesanal no ha sido carente de dicha transformación, tal como se expone en la teoría de recursos y capacidades (LUGO-MORIN et al., 2008).

\subsection{RECURSOS Y CAPACIDADES}

La teoría de los recursos viene a cambiar la perspectiva de las organizaciones totalmente, el modelo de producción se limitaba a la división de tareas y a la delegación de actividades, con la búsqueda de maximizar la producción. El sector artesanal por elección social y cultural de los fabricantes se enfocó a producir en forma limitada; la diferenciación y la diversificación han sido estrategias explotadas en la artesanía, esto ha permitido que dicha actividad subsista. Esta suma de elecciones se entrelazan con la teoría que define a la empresa como una colección única de recursos y capacidades que no se pueden comprar ni vender libremente en el mercado (WERNERFELT, 1984).

En el sector artesanal el conocimiento y aprendizaje en la elaboración de artesanía es un legado familiar y acumulativo, difícil de imitar. El saber se restringe a las organizaciones más arraigadas: el taller familiar, pequeño y de manufactura. El estudio que expone Turok a finales de la década de los ochenta, explica cómo se adoptan las decisiones en la producción de los talleres, la cual se emplea en tres procesos simultáneos:

a) el objeto artesanal se sigue produciendo de la misma manera, no sufre cambio alguno y el comprador es quien le da una nueva función;

b) el objeto se transforma desde su diseño y elaboración, porque el consumidor satisface sus necesidades a través del artesano, y;

c) el surgimiento de nuevas artesanías con gran impacto en las comunidades productoras y el mercado mundial, a causa de sugerencias externas (TUROK, 1988).

El aprendizaje es una capacidad dinámica, aplicado en los procesos productivos de los talleres, son la base central de las capacidades internas que han desarrollado los artesanos, lo que establece un vínculo directo con la ventaja competitiva, e impacta en sus ganancias o pérdidas (HERNÁNDEZ et al., 2007).

Dentro de la innovación en los procesos de producción, el factor de competitividad de los talleres es la creación de su propia tecnología, hecho que ha generado la fabricación de productos variados y diferenciados; ahí reside una acumulación tanto de su propia experiencia, como de la gran variedad de fuentes externas en el diseño, producción, desarrollo y comercialización. La innovación en el sector artesanal exige a los talleres generar los siguientes criterios para adaptarse a la exigencia del mercado:

a) generar conocimientos y materializarlos en innovaciones con productos utilitarios y decorativos;

b) desarrollo y compra de tecnología que disminuyan tiempos y mejoras de calidad en los procesos de fabricación, y;

c) formar sinergia organizativa e imitar rápidamente las innovaciones de sus competidores. 
La problemática comercial que enfrenta la artesanía es sobre dos enfoques contrastados en la perspectiva de consumo actual: son productos culturales sustentados en su valor de origen tradicional; por otra parte, el nuevo posicionamiento en los mercados exige la disminución en tiempos de producción y ubicación en puntos estratégicos de venta (LUGO-MORÍN et al., 2008). Las empresas al contar con recursos y capacidades finitas requieren de emplear activos financieros, físicos y tecnológicos con el conocimiento y aprendizaje que han desarrollado; en el entorno actual los productos se enfrentan a los siguientes factores de mercado:

a) el precio. No hay comparativos claros con los precios de competencia en los artículos artesanales, o entre el valor comercial justo para estos productos;

b) la disponibilidad. Es la posibilidad que tiene el cliente de adquirir un bien o servicio;

c) el conocimiento. La promoción que la empresa realice sobre sus productos para que los consumidores los conozcan;

d) la aceptabilidad. La conformidad, gestión y apoyo que dan los agentes de la cadena de valor para consumir, distribuir, vender o comprar un producto o servicio.

La artesanía enfrenta diversas modificaciones, paulatinamente el artesano debe comprender una realidad: la producción sin enfoque al mercado ya no es sustentable, y ahora debe enfrentarse a la competencia internacional, no solo por ingresar en nuevos consumidores, háblese por medio de la exportación, sino, que sea consumida por el mercado local. Dicha racionalidad ha modificado los esquemas de desarrollo de las empresas, incluso de las zonas industriales locales enfocadas a la producción de bienes.

\subsection{DesarRollo endógeno y SU EFECTO EN LA NUEVA GeOGRAFía ECONÓMicA}

Los sectores manufactureros en México, al igual que el desarrollo industrial han sufrido cambios a partir de la apertura comercial. El proyecto de modernización con simulación al modelo occidental confrontó la iniciación de los tratados de libre comercio con las arraigadas formas de vida mesoamericanas (SALAS y PÉREZ, 2007). Dichas políticas económicas por parte del Estado han modificado los criterios de inversión a nivel microeconómico, las empresas se enfrentan a la competencia de productos con orígenes diversos, lo que genera una dificultad de decisión entre si deben enlazar redes locales para subsistir, o cambiar de actividad productiva.

El sector empresarial enfrenta el impacto en las decisiones de localización, aglomeración y encadenamientos productivos, para determinar la inversión y el costo beneficio de sus operaciones, esto transforma la dispersión geográfica de los entes productores, como es el caso de la artesanía dentro del sector de manufacturas. Las actividades productivas modifican el entorno, por ello, se emplean los conceptos del desarrollo endógeno; que estudia el uso de las potencialidades no explotadas en las comunidades. Para este caso, el lugar de análisis es Tonalá, una de las principales zonas alfareras en la zona metropolitana de Jalisco, México. 
La parte central que plantea la teoría de desarrollo endógeno se sustenta en que: el sistema productivo de los países se transforma con el objeto de desarrollarse, dicho cambio se realiza con el potencial del territorio. Los generadores económicos son las empresas y el Estado. Bajo estos parámetros las economías se organizan a producir de forma espontánea (VÁZQUEZ, 2000). Lo cual demuestra la capacidad de la sociedad para crear sistemas de producción de autoempleo. Los talleres familiares han marcado aspectos con una tendencia competitiva a la evolución de los mercados; la respuesta frontal por parte de las organizaciones ha sido desarrollar el empleo de mano de obra especializada y la postura tradicionalista de algunos a no descentralizar la producción.

El sector artesanal se encuentra en las actividades informales, difiere de las organizaciones establecidas: el trabajo pocas veces es asalariado, la unidad domestica integra la producción que forma la base central del trabajo, y la búsqueda de ganancia u acumulación de activos es difícil de determinar; pero, ello no impide que forme parte del desarrollo social. El ajuste de los sistemas productivos ha afectado a los países, el escenario de competencia cede el paso al desarrollo informacional, el cual supedita la dinámica de los entornos financieros, fortalecido por los cambios tecnológicos y la nueva forma de organización flexible por medio de redes (ibid., 2000).

El enfoque de desarrollo local endógeno en la artesanía debe modificar la perspectiva cultural e ideológica del artesano, el cambio estructural gestado en los sistemas productivos de las organizaciones varía las formas de relación de los actores y sus actividades, así como la dinámica de cambio de aprendizaje y los procesos culturales. Durante años los talleres competían con el entorno local que formaban parte, la estructura actual manufacturera se rige sobre las siguientes estrategias:

Crecimiento de los sectores manufactureros en la región fronteriza, dispersión de la producción anteriormente localizada en el centro del país.

El incremento en los costos de transporte, donde la posición geográfica con el mercado norteamericano ha determinado parte de la dinámica comercial.

Las actividades manufactureras han modificado su orientación al sector externo, al formar redes: economías de escala con el objeto de incrementar la competitividad del comercio intra-industrial.

Formación de centros industriales (clusters) representan una oportunidad de crecimiento para las regiones, debido al mayor desarrollo tecnológico, ampliación del servicio de transporte, especialización en la mano de obra; trae consigo a que las empresas sean cada vez más heterogéneas.

La problemática estructural de los sectores productivos del país se fundamenta en la escasa interacción comercial, dado a que las economías regionales en conjunto se han organizado en sectores estratégicos integrados en su mayoría por empresas transnacionales, que excluye a las pequeñas y medianas empresas, si bien la búsqueda de producción por medio de las economías de escala no es un factor de competitividad, pero, si fomenta la oportunidad de comercializar productos al exterior, lo que genera una desigualdad en conocimiento, ingresos y crecimiento en las regiones; la colaboración interempresarial y el enfoque al exterior son factores determinantes de desarrollo económico en el entorno actual (MENDOZA y PÉREZ, 2007). 
El modelo de integración a los mercados mundiales ha modificado en gran parte la estructura comercial de México. El cambio de políticas económicas de emplear la sustitución de importaciones como soporte del desarrollo industrial, a implementar el modelo de liberación económica tuvo como base de crecimiento al sector manufacturero de la iniciativa privada (GONZÁLEZ y DUSSEL, 2001). Dichos cambios se favorecieron en parte por las inversiones en los sectores con comercio fronterizo y a la ventaja comparativa en costos hacia el mercado norteamericano, por medio de la maquila, al emplear programas de importación temporal y exportar productos ya ensamblados, cabe destacar que esto originó el desarrollo de los centros industriales.

La perspectiva de Krugman, define a los centros industriales como a los generadores de crecimiento en la teoría de la nueva geografía económica. Este fenómeno se genera por la búsqueda de economías de escala que permitan mayor margen de ganancia a los entes comerciales; la producción y aglomeración de inversión por medio de las empresas se debe a causas de economía externa y costo de localización, el aumentar la producción y disminuir los costos de transporte se han determinado como estrategia de subsistencia (MENDOZA y PÉREZ, 2007).

La necesidad de explicar la transformación y el crecimiento económico de las regiones vienen aunados a los cambios en la reorganización de la producción. El aporte central de la nueva geografía económica es explicar la estructura de la producción, se ha generado el modelo económico de cluster: formación vertical de los sectores, se entrelazan produciendo bienes, la dinámica económica subsiste por las conexiones hacia delante y hacia atrás, al ser proveedores de bienes intermedios a las empresas o sectores interconectados (FUJITA y KRUGMAN, 2004).

La evolución de la economía de mercado dificulta el desarrollo de las empresas locales. En Tonalá, con la gran diferenciación de productos y la localización de empresas de logística y transporte, pudiesen generar las características para emplear un distrito industrial enfocado en la producción de artesanía, a su vez, su cercanía con Tlaquepaque, municipio enfocado mayoritariamente al turismo para ser su principal proveedor de artículos; no obstante, la ardua competencia local crea diferencias que desincentivan la cooperación, aunado al escaso capital que cuentan los talleres.

La artesanía, al ser un producto manufacturado, ha enfrentado graves cambios en la localización de la producción y consumo, tanto en los mercados internos e internacionales. La dispersión, y la aparición estratégica que han obtenido nuevas zonas productoras de artesanía con la apertura comercial ha traído consigo que las ventajas competitivas como: la ubicación estratégica, el grado de infraestructura, la proporción de personal y el carácter tradicional e indivisible de los productos modifiquen la exigencia de sus mercados cautivos (CORREA et al., 2009).

El siguiente cuadro, sintetiza los factores que forman parte de los intercambios comerciales de la artesanía en Tonalá, el territorio ha tomado una nueva dinámica comercial, un factor importante de crecimiento en la zona ha sido la aglomeración de comerciantes de diversas parte del país, al formar una gran oferta de productos y una importante atracción para los compradores y turistas. Creando así un tejido en la cadena productiva, mediante las interacciones de intercambio y la creación del capital social: basado en situaciones de confianza, reglas, cooperación-competencia (cuadro 1). 


\begin{tabular}{|c|c|c|}
\hline \multicolumn{3}{|c|}{$\begin{array}{c}\text { CUADRO } 1 \\
\text { AGLOMERACIÓN PRODUCTIVA EN LOS TALLERES DE ARTESANÍA DE TONALÁ, JALISCO }\end{array}$} \\
\hline FACTORES & VENTAJAS & DESVENTAJAS \\
\hline Salario & $\begin{array}{l}\text { Relativamente es bajo, fijado a des- } \\
\text { tajo; conforme la productividad del } \\
\text { trabajador. }\end{array}$ & $\begin{array}{l}\text { La mano de obra especializada se } \\
\text { concentra en talleres que ofrecen } \\
\text { mejor sueldo y prestaciones. }\end{array}$ \\
\hline $\begin{array}{l}\text { Costo de trans- } \\
\text { porte }\end{array}$ & $\begin{array}{l}\text { Cercanía con importantes merca- } \\
\text { dos de Jalisco y Nacionales: Distrito } \\
\text { Federal, Guanajuato, Querétaro. }\end{array}$ & $\begin{array}{l}\text { Costo excesivo para envió a la } \\
\text { frontera con Estados Unidos. }\end{array}$ \\
\hline $\begin{array}{l}\text { Importancia en } \\
\text { el mercado }\end{array}$ & $\begin{array}{l}\text { Bienes diferenciados, representati- } \\
\text { vos, culturales, empleados para uso } \\
\text { decorativo y utilitario. }\end{array}$ & $\begin{array}{l}\text { No son bienes de primera necesidad, } \\
\text { no existen precios comparativos. }\end{array}$ \\
\hline $\begin{array}{l}\text { Las unidades } \\
\text { domesticas }\end{array}$ & $\begin{array}{l}\text { Concentración importante de tal- } \\
\text { leres productivos, proveedores de } \\
\text { insumos y comerciantes (interme- } \\
\text { diarios). }\end{array}$ & $\begin{array}{l}\text { Nula cooperación, las innovacio- } \\
\text { nes en los productos son copiadas } \\
\text { o imitadas. }\end{array}$ \\
\hline $\begin{array}{l}\text { Economías de } \\
\text { escala }\end{array}$ & $\begin{array}{l}\text { La oferta y aglomeración de diver- } \\
\text { sos comerciantes nacionales ofrece } \\
\text { múltiples productos para la conso- } \\
\text { lidación. }\end{array}$ & $\begin{array}{l}\text { La producción limitada incrementa } \\
\text { el costo de transporte en los pro- } \\
\text { ductos. }\end{array}$ \\
\hline Tecnología & $\begin{array}{l}\text { Disminuye los lapsos de produc- } \\
\text { ción; la mayoría a pesar de ello es } \\
\text { semi-industrial: Torno, buril, mez- } \\
\text { cladora. }\end{array}$ & $\begin{array}{l}\text { La decoración es la parte del proce- } \\
\text { so productivo que emplea la mayor } \\
\text { mano de obra y tiempo. }\end{array}$ \\
\hline
\end{tabular}

Fuente: Elaboración propia con base a Fujita y Krugman, 2004.

Un análisis actual sobre un sector productivo es imprescindible el excluir al comercio internacional y los efectos que causa en la estructura económica, al igual que en México, en Tonalá la producción artesanal ha experimentado cambios, uno de ellos es que los talleres tradicionales han disminuido su nivel de producción. Contrastado con el auge exportador de los años ochenta, la disminución de la productividad de los talleres, aunado a la competencia internacional de artesanías chinas, la limitada especialización de la industria de servicios a nivel local, así como la falta de créditos y al comercio desleal son las principales causas.

\subsection{EL COMERCIO INTRAINDUSTRIAL Y LA GENERACIÓN DE VENTAJA COMPETITIVA}

La apertura al exterior de México a partir de 1987 orientó el enfoque del sector manufacturero hacia el comercio internacional. El estudio analiza el comercio intraindustrial: que se define al comercio de bienes que pertenecen a una misma etapa productiva y a un mismo producto. Los cambios estructurales de la economía en México exigen a la artesanía afrontar cambios tanto en la producción como en la comercialización. El análisis 
de Cuevas detalla que a partir del periodo 1940-1970 aumentó el número de galerías y tiendas de artesanía (Cuevas, 2007). Esto llevó a un incremento de oferta artesanal en México a través del turismo.

Las alfarerías con talleres y empleados se convirtieron en comercializadoras y exportadoras con artesanías de todos los rincones de México, dio como resultado el surgimiento de talleres semi-industriales. Estos talleres se centraron en la producción y venta directa a clientes o intermediarios en sus instalaciones. El aumento en la producción por parte de los talleres manufactureros, así como la elevada demanda por los productos artesanales generó que los talleres de manufactura se volvieran exportadores, y se mantuvieran de la maquila; siendo los talleres familiares sus principales proveedores (ibid., 115). En Tonalá se observa una conversión del taller manufacturero hacia la tienda comercializadora de productos importados, así como de artesanías nacionales. Los talleres manufactureros han logrado subsistir, a pesar de contar con varias generaciones familiares trabajando debido a que recurren al capital social que se han venido construyendo a lo largo de los años, en el que la familia nuclear es el principal sostén, seguido de la familia extendida, posteriormente los amigos y conocidos.

La problemática económica para el artesanado en México a partir de la apertura económica va ligado con la competitividad internacional del sector, fundamentalmente porque la mayoría de la producción se enfocaba al mercado norteamericano, si bien, el Tratado de Libre Comercio (1994) viene a fraguar ventajas comerciales para las empresas mexicanas por la ubicación, preferencia arancelaria y el tamaño de mercado, con todo y ello la actividad artesanal no posee la visión social del productor, la capacidad tecnológica, ni el capital para transformar en años a las microempresas de carácter doméstico (NOVELO, 2008).

Con respecto a las exportaciones e importaciones de artesanía, se toma la fracción arancelaria 69139099 para el comparativo de análisis de los productos y el intercambio comercial. Las exportaciones a nivel nacional de artesanía se han orientado al mercado norteamericano y canadiense, la disminución del envío de mercancías impactó en un $26 \%$ y $35 \%$ en los envíos comparativos de 2006 y 2007 . Adquiere mayor importancia el mercado Europeo en el lapso de 2006 y 2007, pero presenta una caída drástica al siguiente año. Por lo que se puede argumentar que es un mercado inestable (cuadro 2). La cercanía geográfica y el menor costo de transporte para la llegada de mercancía son aspectos generadores de la dinámica comercial de estos productos. 


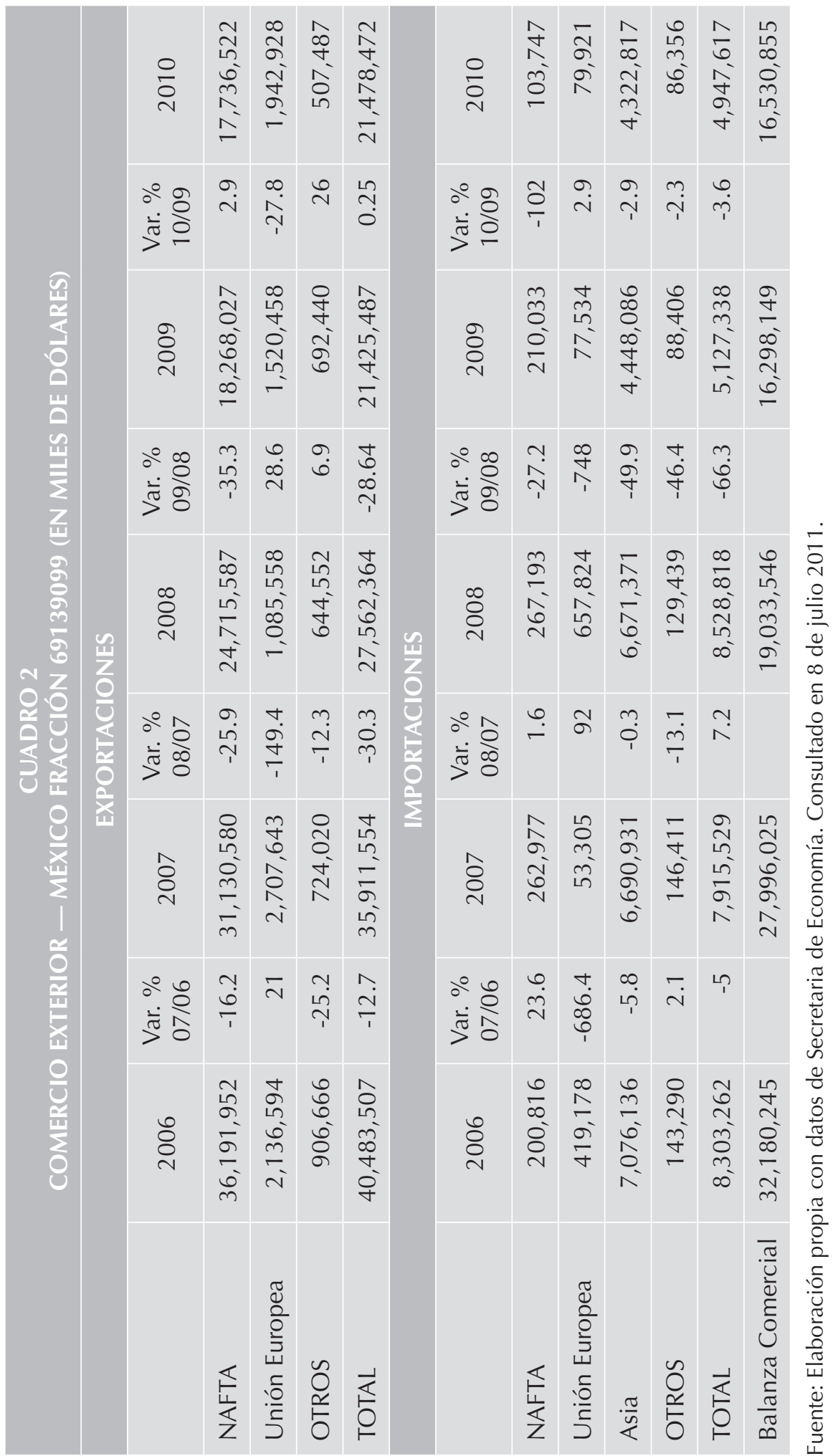


El mercado externo de las artesanías está enfocado hacia Estados Unidos y Canadá. El incremento del 3\% en el 2010 de las exportaciones dentro del TLCAN plantea un punto positivo de la demanda, mercado que acapara el $82 \%$ del total de operaciones al exterior (cuadro 3).

Las importaciones de México no representan una amenaza para el sector, sin embargo, en los mercados de consumo es progresivo el cambio por productos de origen asiático. Para el 2010 la disminución fue del 3.6\% en la importación; disminuyó la compra de productos provenientes de Asia, e incrementó en un 3\% en la compra de artículos europeos (cuadro 3).

\begin{tabular}{|c|c|c|c|c|c|c|c|c|c|}
\hline \multicolumn{10}{|c|}{$\begin{array}{c}\text { CUADRO } 3 \\
\text { COMERCIO EXTERIOR - MÉXICO FRACCIÓN } 69139099\end{array}$} \\
\hline \multicolumn{2}{|c|}{ EXPORTACIONES } & \multicolumn{8}{|c|}{ EN PORCENTAJE DE PARTICIPACIÓN DE MERCADO } \\
\hline & 2006 & $\begin{array}{l}\text { Var. \% } \\
07 / 06\end{array}$ & 2007 & $\begin{array}{l}\text { Var. } \% \\
08 / 07\end{array}$ & 2008 & $\begin{array}{l}\text { Var. } \% \\
09 / 08\end{array}$ & 2009 & $\begin{array}{l}\text { Var. } \% \\
10 / 09\end{array}$ & 2010 \\
\hline NAFTA & 89.40 & -2.35 & 86.69 & 2.68 & 89.67 & -3.76 & 85.26 & -2.22 & 82 \\
\hline $\begin{array}{l}\text { Unión } \\
\text { Europea }\end{array}$ & 5.28 & 0.17 & 7.54 & -0.14 & 3.94 & 0.22 & 7.10 & 0.18 & 9 \\
\hline OTROS & 2.24 & 0.00 & 2.02 & 0.01 & 2.34 & 0.03 & 3.23 & -0.02 & 2.3 \\
\hline \multicolumn{10}{|c|}{ IMPORTACIONES } \\
\hline NAFTA & 2.42 & 0.03 & 3.32 & -0.01 & 3.13 & 0.04 & 4.10 & -0.04 & 2.1 \\
\hline $\begin{array}{l}\text { Unión } \\
\text { Europea }\end{array}$ & 5.05 & -0.03 & 0.67 & 0.54 & 7.71 & -0.09 & 1.51 & 0.00 & 1.6 \\
\hline OTROS & 85.22 & -0.58 & 84.53 & -4.93 & 78.22 & 7.40 & 86.75 & 0.54 & 87.3 \\
\hline
\end{tabular}

Fuente: Elaboración propia con datos de Secretaria de Economía. Consultado en 8 de julio de 2011.

El bloque económico del TLCAN para la artesanía se ha compactado muy poco: del 85.2\% del 2006, al 82\% de la participación total del mercado en el 2010. Independientemente que Canadá para el 2010 cuente con un importante volumen de importación y un incremento (25\%) con respecto al 2009, al ser el segundo país destino de las exportaciones. El mercado norteamericano, principal importador, en 2010 disminuyó (4.1\%), con la disminución del 2.22\% para envíos al NAFTA, en 2010; es en parte por la fuerte competencia de productos asiáticos, el ingreso de productos latinoamericanos donde principalmente Perú, Guatemala, Chile y Colombia han captado participación del mercado con propuestas novedosas, y por la diversificación estratégica de las empresas mexicanas, con el objetivo de incrementar la dinámica al mercado europeo.

El comercio exterior de artesanía de Jalisco conforma parte importante de la dinámica de exportación. Destaca Tonalá, con el 55\% de participación en el mercado exterior para el año 2010, un incremento del 95\%, con respecto al 2009 (cuadros 4 y 5). Del 
comercio formal representa el municipio con mayor volumen comercial de artesanía, realizado por las tiendas ubicadas en la zona comercial o por intermediarios con oficinas y operaciones en el municipio; el informal es realizado en las calles aledañas y ofrecido a turistas con mercancía procedente de talleres familiares.

\begin{tabular}{|c|c|c|c|c|c|c|c|}
\hline \multicolumn{8}{|c|}{$\begin{array}{c}\text { CUADRO } 4 \\
\text { COMERCIO EXTERIOR DE ARTESANÍA — ZONA METROPOLITANA DE JALISCO (EN DÓLARES) }\end{array}$} \\
\hline \multicolumn{2}{|c|}{ EXPORTACIONES } & \multicolumn{6}{|c|}{ PORCENTAJE DE VARIACIÓN ANUAL } \\
\hline Fracción 6913 & 2007 & $\begin{array}{l}\text { Var. } \% \\
08-07\end{array}$ & 2008 & $\begin{array}{l}\text { Var. } \% \\
09-08\end{array}$ & 2009 & $\begin{array}{l}\text { Var. \% } \\
10-09\end{array}$ & 2010 \\
\hline Guadalajara & 17,714 & 76.6 & 75,886 & 64.1 & 211,821 & 66.8 & 638,154 \\
\hline Tlaquepaque & 626,106 & 17 & 754,863 & -57 & 480,632 & -3.7 & 463,448 \\
\hline Tonalá & 37,480 & -52.4 & 24,589 & 82.5 & 140,781 & 94.9 & $2,762,400$ \\
\hline Zapopan & 120,529 & 69.7 & 398,080 & -27.3 & 312,506 & 55 & 694,900 \\
\hline Total & $1,077,087$ & 38.5 & $1,751,108$ & -13.3 & $1,544,678$ & 69 & $4,997,301$ \\
\hline \multicolumn{8}{|c|}{ IMPORTACIONES } \\
\hline Fracción 6913 & 2007 & $\begin{array}{l}\text { Var. } \% \\
08-07\end{array}$ & 2008 & $\begin{array}{l}\text { Var. } \% \\
09-08\end{array}$ & 2009 & $\begin{array}{l}\text { Var. \% } \\
10-09\end{array}$ & 2010 \\
\hline Guadalajara & 1,973 & 54.8 & 4,364 & 91.5 & 51,557 & 51.8 & 107,131 \\
\hline Tlaquepaque & 1,345 & 40.9 & 2,277 & 94.8 & 43,945 & 51.7 & 91,020 \\
\hline Tonalá & 0 & 0 & 0 & 0 & 0 & 0 & 0 \\
\hline Zapopan & 150 & 98.8 & 13,195 & -11.4 & 11,845 & 26.3 & 16,084 \\
\hline Total & 120,484 & 68.2 & 378,860 & 15.8 & 450,156 & 12 & 511,823 \\
\hline $\begin{array}{l}\text { Balanza } \\
\text { Comercial }\end{array}$ & 956,603 & & $1,372,248$ & & $1,094,522$ & & $4,485,478$ \\
\hline
\end{tabular}

Fuente: Elaboración propia con datos de SEIJAL. Consultado el 8 de julio de 2011.

\begin{tabular}{|c|c|c|c|c|c|c|c|}
\hline \multicolumn{8}{|c|}{$\begin{array}{l}\text { CUADRO } 5 \\
\text { COMERCIO EXTERIOR DE ARTESANÍA - ZONA METROPOLITANA DE JALISCO } \\
\text { (EN PORCENTAJE) }\end{array}$} \\
\hline \multicolumn{2}{|c|}{ EXPORTACIONES } & \multicolumn{6}{|c|}{ EN PORCENTAJE DE PARTICIPACIÓN DE MERCADO } \\
\hline Fracción 6913 & 2007 & $\begin{array}{l}\text { Var. \% } \\
08-07\end{array}$ & 2008 & $\begin{array}{l}\text { Var. \% } \\
09-08\end{array}$ & 2009 & $\begin{array}{l}\text { Var. \% } \\
10-09\end{array}$ & 2010 \\
\hline Guadalajara & 1.6 & 0.12 & 4.3 & 1.29 & 13.7 & -0.13 & 12.7 \\
\hline Tlaquepaque & 58 & -6.45 & 43 & -3.7 & 31.1 & -2.01 & 9.2 \\
\hline Tonalá & 3.4 & -0.03 & 1.4 & 0.7 & 9.1 & 25.45 & 55.2 \\
\hline Zapopan & 11 & 2.66 & 22.7 & -0.51 & 20.2 & -0.88 & 13.9 \\
\hline
\end{tabular}




\begin{tabular}{|c|c|c|c|c|c|c|c|}
\hline \multicolumn{8}{|c|}{$\begin{array}{c}\text { CUADRO } 5 \\
\text { COMERCIO EXTERIOR DE ARTESANÍA - ZONA METROPOLITANA DE JALISCO } \\
\text { (EN PORCENTAJE) }\end{array}$} \\
\hline \multicolumn{2}{|c|}{ EXPORTACIONES } & \multicolumn{6}{|c|}{ EN PORCENTAJE DE PARTICIPACIÓN DE MERCADO } \\
\hline \multicolumn{8}{|c|}{ IMPORTACIONES } \\
\hline Fracción 6913 & 2007 & $\begin{array}{l}\text { Var. \% } \\
08-07\end{array}$ & 2008 & $\begin{array}{l}\text { Var. \% } \\
09-08\end{array}$ & 2009 & $\begin{array}{l}\text { Var. \% } \\
10-09\end{array}$ & 2010 \\
\hline Guadalajara & 1.64 & -0.01 & 1.1 & 1.17 & 11.4 & 1.99 & 20.9 \\
\hline Tlaquepaque & 1.12 & 0 & 0.6 & 0.88 & 9.7 & 1.42 & 17.7 \\
\hline Tonalá & 0 & 0 & 0 & 0 & 0 & 0 & 0 \\
\hline Zapopan & 0.12 & 0.11 & 3.4 & -0.02 & 2.6 & 0.02 & 3.1 \\
\hline
\end{tabular}

Fuente: Elaboración propia con datos de SEIJAL. Consultado el 8 de julio de 2011.

El sector de fabricación de artesanías nacional no es comparable a la producción industrial realizada en Asia o en Europa, debido al empleo de técnicas coloniales en la mayoría de Estados de la Republica. El uso de maquinaria industrial está totalmente desligado de la actividad. El aspecto importante es el cambio en la producción de los talleres, al no ser competitivos para proveer de bienes para uso doméstico la tendencia en la innovación ha sido fabricar bienes decorativos.

La falta de interacción de los talleres familiares con los mercados internacionales ha generado efectos irreversibles: falta de conocimiento de las nuevas demandas en diseño, decoración o el uso requerido por el consumidor, la total dependencia de los compradores y la carencia de sinergia entre unidades productivas; paulatinamente ha causado una disminución del comercio al exterior de artesanía.

Una de las causas fundamentales es la pérdida en competitividad de la producción artesanal; el objetivo de analizar el intercambio de productos de carácter intraindustrial es debido a que este no se condiciona a ventajas comparativas en precios, el costo comparativo entre los artículos de México cuentan con un precio alto respecto a los manufacturados de Estados Unidos.

La ubicación geográfica con el mercado norteamericano juega un papel importante, sobre todo para zonas fronterizas de producción, ha permitido el desarrollo de zonas de maquila importantes para la dinámica económica. El problema con el sector artesanal es que la actividad no se encuentra vinculada o integrada a un modelo de economías de escala o a una integración de procesos productivos con otros países, hace que la actividad enfrente una desventaja desproporcional a las exigencias actuales de mercado (MORENO y Palerm, 2001).

Dentro de los factores competitivos en la artesanía se encuentra la intensificación del comercio intraindustrial horizontal, tiene mayor oportunidad de ingreso, debido a que se basan en el intercambio de bienes similares, pero diferenciados en marca, publicidad, localización geográfica, estilo y disponibilidad (ibid., 790); el mercado de expor- 
tación de artesanía hacia norte américa se ha modificado en función de la competencia entre empresas, aspectos como la estandarización y precios son ahora fundamentales.

La economía y la diversificación de las empresas con los productos han tomado una tónica intensificada al respecto con el comercio intraindustrial: Menores costos de producción; búsqueda de participación en el comercio internacional; diversificación de bienes, con mayores niveles de utilidad para el consumidor.

Dentro de los intercambios comerciales la diferenciación ha sido un factor prominente en la artesanía, dentro de la competencia entre empresas los productos presentan diversos matices para poder cumplir con las exigencias de los consumidores, las siguientes son bases importantes para la diferenciación competitiva:

a) bienes sustitutos en el consumo pero que no utilizan los mismos insumos de producción;

b) bienes que utilizan los mismos insumos de producción pero tienen distintos usos en el consumo;

c) bienes sustitutos tanto en el uso como en los insumos (GONZÁLEZ y DUSSEL, 2001).

Dichos aspectos han modificado la demanda de artesanía hacia los mercados internacionales, sobre todo por los bienes sustitutos (los insumos y el desarrollo de tecnología en los sectores productivos asiáticos por la dureza de sus productos cerámicos como "el caolin") a su vez las economías de escala en producción, donde las fábricas pueden abastecer la demanda de fuertes volúmenes, hacen que la artesanía mexicana se oriente a la búsqueda de estilo y calidad en acabados.

La alta competitividad en los sectores productivos se consolida con la apertura internacional de las economías, y con la diversificación de las inversiones en zonas económicas de alto potencial. Estos aspectos modifican el entorno de las empresas, lo que exige como respuesta la construcción de estrategias o herramientas que se adecuen a la situación actual, una de ellas es la ventaja competitiva (PORTER, 1990).

La teoría de la ventaja competitiva se adecua a la búsqueda de resultados en las organizaciones, la necesidad de determinar el papel de la industria que rige en la actualidad las operaciones comerciales es vital para el desarrollo y consecución de los objetivos internos empresariales, donde ahora imperan:

Rendimientos crecientes y maximización de los factores productivos;

Empresas capaces de diferenciar productos a costos bajos;

Búsqueda de cubrir la demanda de diversos consumidores (LÓPEZ y RODIL, 2008).

El modelo de economías de escala en la producción, ha concentrado a los sectores en una dinámica intensa por abastecer las demandas. La agrupación de empresas organizadas en divisiones de trabajo, especializadas en fases productivas y por sectores, genera volúmenes de producción difíciles de imitar por el sector artesanal, el factor fundamental empleado es la mano de obra (RODRÍGUEZ, 17: 2006). 
En el caso del estudio se emplea la ventaja competitiva para culminar el modelo de exigencia para las empresas que incursionan en los mercados internacionales de artesanía, al citar aspectos que algunos talleres artesanales no conciben al día de hoy, porque no son participes directamente del comercio internacional.

El estudio de Porter (1990) se enfoca al desarrollo de estrategias que emplean las empresas con el objeto de competir en la industria. El autor plantea dos conceptos integradores requeridos en el contexto actual: cadena de valor (interno) y fuerzas competitivas (externo); difícilmente una empresa que no concibe en el ambiente actual cuales son las operaciones internas que generan valor al cliente, y como se encuentra el sector donde realiza operaciones, queda propensa a desaparecer.

Los grados de competencia se incrementan, como en el caso de envío de productos de exportación, sobre la artesanía, un bien demandado internacionalmente, pero, que en la estructura de libre mercado se encuentran condicionados a precios, costos, tiempos y relaciones cooperativas: todos estos factores acumulados para que el cliente tome la decisión de compra.

Con base al supuesto anterior, surgen preguntas sobre el cómo evaluar la rentabilidad y participación de la artesanía tanto en el mercado local como internacional; al partir que el mercado es dinámico, independientemente de la innovación, flexibilidad y conocimiento que los talleres artesanales han desarrollado a lo largo de los cambios históricos en la economía.

El comercio se determina por diferencias de productividad, tecnología, factores productivos y la competencia. Estos aspectos no se han tomado en cuenta por parte de las familias productoras, cuya visión, si bien valida, porque ha permitido la presencia del oficio y el posicionamiento de los productos: ha dejado poco margen de maniobra en la pugna por obtener ingresos.

El cuadro 6, detalla alguno de los cambios estratégicos y competitivos realizados por los talleres artesanales a través del tiempo en México, efectuados con el objetivo de mantenerse en el ámbito comercial. El ambiente ha sido un determinante en el desarrollo tanto de ventajas competitivas para las empresas, como causal para que estas desaparezcan. La estructura del sector tiene influencia al determinar las reglas de juego competitivas así como las posibilidades estratégicas que probablemente puedan utilizarse. 


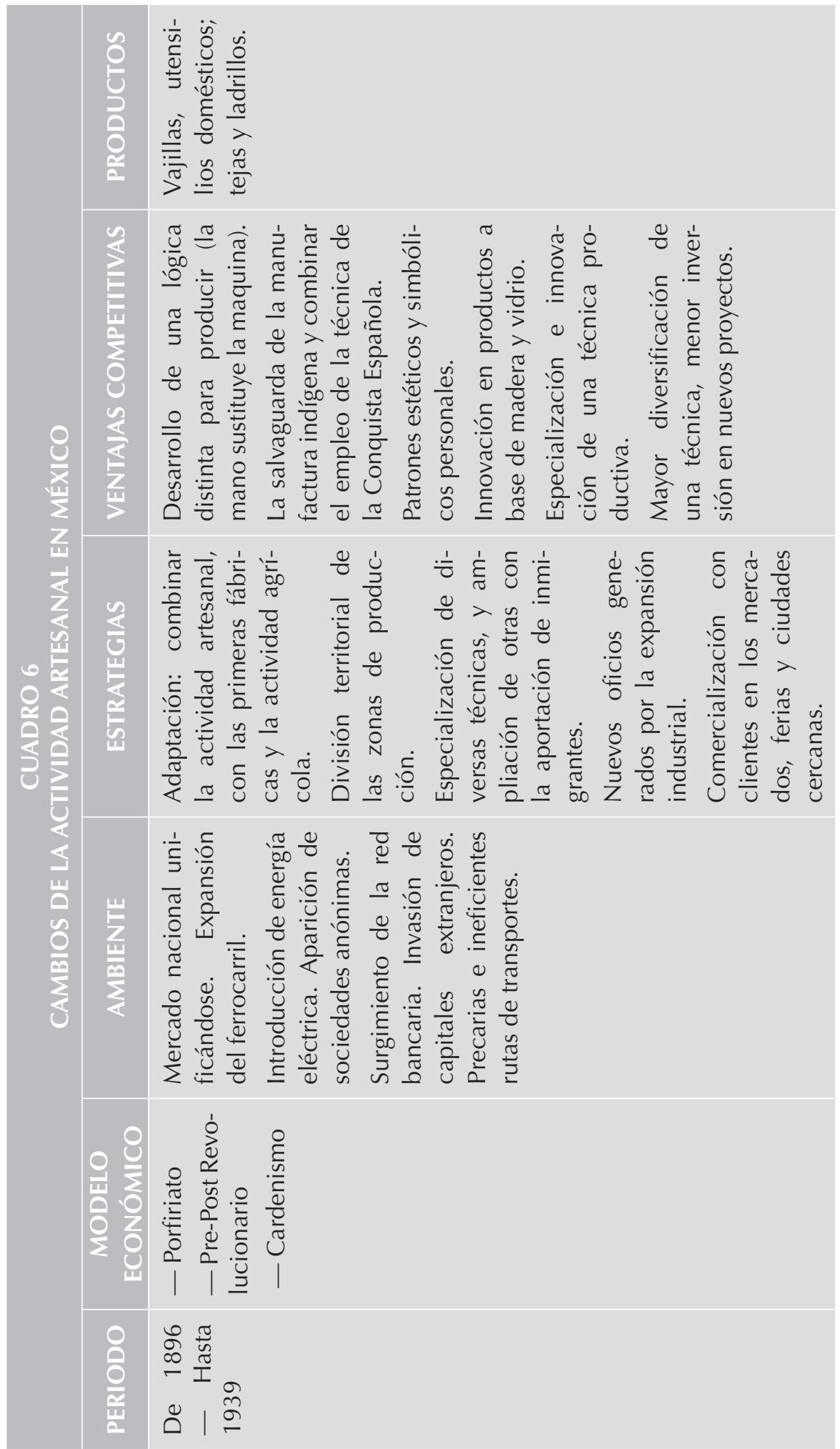




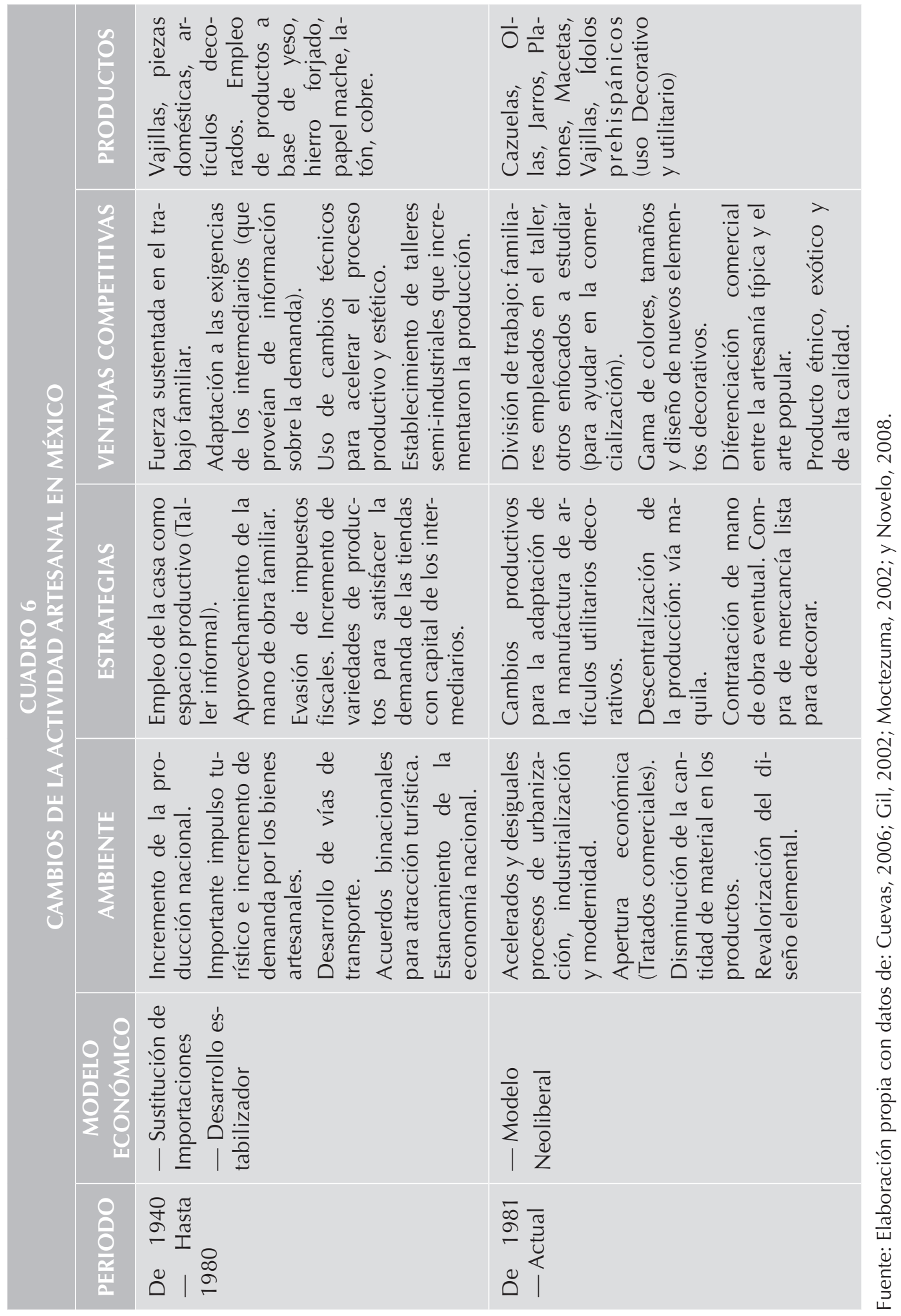


El carácter de la formulación de la estrategia consiste en relacionar a la empresa con su entorno, al encontrar una posición en dicho sector en el cual pueda competir mejor contra las fuerzas competitivas (ibid., 19). Pudiese encontrarse una contracción total en la actividad artesanal con respecto a entender el ambiente, y por medio de ello crear estrategias, debido a dos causas fundamentales:

La visión del productor (artesano) se ha limitado en mayor parte a fabricar productos y cumplir la demanda de los intermediarios;

El binomio producción - comercialización: se supedita al amor por la profesión, esto es; la variable y finalidad no es obtener capital, sino que esta permanezca.

El ambiente competitivo para el artesano cambia abruptamente con el último modelo económico implementado (Neoliberal), las presiones exógenas tanto de los nuevos consumidores y compradores impacta directamente en los volúmenes de producción. Los talleres enfrentan una dinámica donde las ventajas competitivas provienen de la disminución de costos. El empleo de estrategias en los sectores manufactureros son determinadas por la tecnología e innovación, a rubros específicos como: calidad, entrega y flexibilidad; y la integración con la satisfacción del cliente.

El sector artesanal, por su carácter informal, se ha modificado con estrategias empleadas de dentro hacia fuera (planteadas en el taller hacia el mercado); las pequeñas cantidades de producto fabricado los han llevado a una gran diversificación en la orientación con el cliente; una base fundamental para su subsistencia.

Sin embargo, es deficiente que se conciba de parte de los talleres un entorno estático, donde impere la cooperación del intermediario, que funja como inversor y facilitador siempre de soluciones al comercio internacional. El siguiente punto detalla la investigación de caso sobre un taller artesanal de Tonalá; se detallan aspectos sobre producción, comercialización e innovación tecnológica en la fabricación de artesanía.

\section{Estudio de Caso: Estructura del Taller Artesanal Tonalteca}

El realizar un análisis al interior de un taller artesanal tiene como objetivos: identificar las fortalezas que ha desarrollado para mantener su supervivencia, determinar cuáles son sus ventajas competitivas internas y el enfoque que toma el artesano en la generación de innovaciones de producción y comercialización ante el ambiente actual.

Wernerfelt (1984) define a la empresa innovadora: como la que acumula un saber que a futuro le permitirá consolidar habilidades propias para renovarse constantemente mediante la gestión de sus recursos. Los procesos productivos son la base central de las capacidades internas que han desarrollado los artesanos (HERNÁNDEZ et al., 2007: 375), sin embargo, la creciente competencia global hace más difícil de controlar cualquier mercado, y la rápida evolución tecnológica acorta el ciclo de la vida de los productos.

La investigación se orientó a identificar las variables internas del negocio a través de un estudio de caso; una descripción de las ventajas que le permiten competir en el sector 
artesanal, y evaluar la situación actual de los recursos y capacidades que poseen. Se empleó una entrevista semiestructurada y a fondo con el propietario con el fin de abstraer el enfoque de su negocio. Las preguntas de investigación son exploratorias: ¿Cuál es la situación interna de las áreas productivas del taller estudiado? Y ¿Qué factores cuenta el taller que generan ventajas internas con respecto a las empresas establecidas?

El estudio realizó un comparativo con el enfoque de: habilidades, situación actual, estado de innovación, liderazgo del artesano, visión del mercado, perspectiva de sus empleados; en el ámbito de un taller artesanal de productos cerámicos: barro (técnica bruñido ${ }^{(3)}$ y greta). El estudio compara la situación interna de la empresa con respecto a empresas artesanales consolidadas. La evaluación de las oportunidades e identificación de los problemas internos del taller bosqueja las bases críticas para participar en el ingreso de artesanía a un mercado extranjero.

Martínez (2006) indica que el método de estudio de caso es una metodología rigurosa que permite estudiar un tema determinado. La exigencia en el mercado de la artesanía es que el factor de permanencia debe desarrollarse por medio de los productos diferenciados, el proceso de innovación del artesano lo ha adoptado como una capacidad de aprendizaje gradual e incrementable, al adquirir conocimientos por medio de la repetición y experimentación. Todo ello canalizado hacia el proceso del producto.

El tamaño pequeño de los talleres artesanales permite una respuesta rápida a los cambios del entorno y a la flexibilidad de una integración como eslabón en las cadenas productivas; sin embargo, la innovación en la comercialización es deficiente. El complejo canal de redes construido por personas $u$ organizaciones que son requeridos para hacer llegar el producto a los diversos mercados es una de las variables que impacta en las ventas del taller al igual que del sector artesanal.

El estudio recopila información y analiza el taller a través del tiempo: en las áreas productivas, planeación e innovación tecnológica; lo anterior con el fin de determinar los resultados en comparación con los factores estratégicos de empresas que han logrado mantenerse en el sector, por tratarse de talleres con la tendencia a la innovación y a la participación dentro de mercados extranjeros.

\section{Taller Artesanal: Resultados Obtenidos}

El taller denominado DIJA se conformó hace 7 años (2004), es una empresa relativamente nueva. Está clasificado como microempresa por el número de empleos: son 4 (entre familiares y empleados), cuyo trabajo se otorga por proyecto (pedidos), estos son por temporadas fuertes o por contacto con intermediarios. Su actividad principal es la elaboración de productos artesanales: platos, tasas, loza, vasos de cerámica; con el

(3) Técnica prehispánica: La pieza se alisa al emplear una piedra de río, para enseguida darle el baño que los artesanos suelen llamar "matiz". Se dejan secar y se trazan con pincel diversos motivos: Una vez que la pieza se ha secado se le da otro baño, se deja secar. En este caso se utiliza un bruñido de pirita, con el que la superficie queda en extremo brillosa. Todos estos pasos se efectúan antes de la cocción. La loza azteca o (Greta) que toma su nombre del decorado a base de grecas y formas indígenas. 
empleo de las siguientes técnicas: barro bruñido, barro greta y matiz principalmente. Se ubica en el municipio de Tonalá, que es parte de la zona metropolitana de Guadalajara, la segunda ciudad más importante de México (mapa 1).

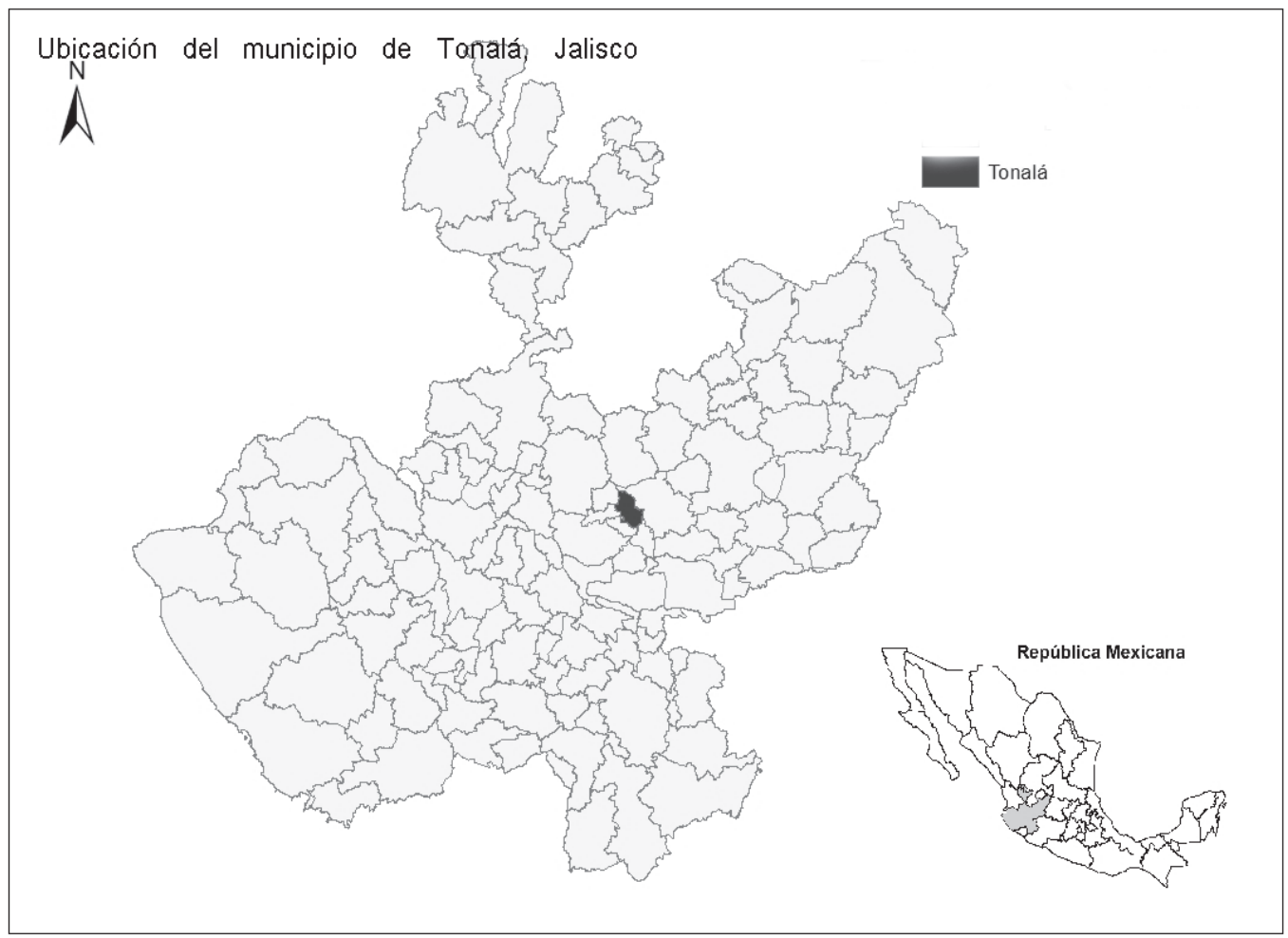

Mapa 1. Ubicación del municipio de Tonalá, Jalisco, México.

En la actualidad, la empresa experimenta una disminución en las ventas. Al enfrentarse a la competencia sin información y sin estrategias, pone al taller en una situación preocupante; sin embargo, la capacidad tecnológica, y la facilidad para obtener mano de obra calificada, le permite replantear esta situación actual.

El propietario del taller cuenta con 37 años, se formó en la escuela de artes plásticas de la segunda Universidad más importante de México, la Universidad de Guadalajara, donde estudió dibujo y pintura a nivel técnico. El aprendizaje y saber acumulado por la herencia de conocimientos básicos por parte de su padre, a la par de haber trabajado en diferentes talleres, le facilitó aprender además de diversas técnicas artesanales, la división de trabajo que permite la especialización y los procesos de producción de las técnicas distintivas de Tonalá.

El rasgo distintivo del taller es el aspecto tecnológico: la creación de su propia tecnología permite adecuar el proceso, mejorar la calidad y realizar operaciones en menor tiempo. Este aspecto es fundamental debido a que permite una ventaja con respecto a otros talleres, el innovar y mejorar los procesos productivos con el fin de obtener mayor producción. 
Dentro de las diversas tendencias de producción y aprendizaje a través del tiempo en el taller, la complejidad de acceder a nuevos proyectos conforme el taller obtuvo maquinaria y la disminución en la cantidad de mano de obra. Se observa que la incorporación de la tecnología genera mayores ingresos. Otro aspecto importante es: a mayor complejidad de los proyectos, el tiempo se incrementó por el factor aprendizaje y la necesidad de adecuación en las líneas de producción.

La disminución del costo de mano de obra conforme el proyecto es más complejo, en términos de la especialización de la mano de obra calificada y la obtención de incrementar la productividad en la mercancía con mayor valor agregado, se visualiza en el precio final (Cuadro 7). La implementación de tecnología funge como un factor de productividad: elaborar productos con empleo de mano de obra y precios bajos; a disminuir al 50\% la mano de obra, e incremento en los precios.

\begin{tabular}{|c|c|c|c|c|c|c|c|c|c|c|}
\hline \multicolumn{11}{|c|}{ CUADRO 7 PRODUCCIÓN DEL TALLER DIJA } \\
\hline & $\begin{array}{c}\text { EMPLEA- } \\
\text { DOS } \\
\text { (TEMPO- } \\
\text { RALES) }\end{array}$ & $\mathrm{H}$ & M & $\begin{array}{l}(400 \\
\text { PIEZAS) }\end{array}$ & $\begin{array}{c}(\mathrm{MO}) \\
(1)\end{array}$ & $\begin{array}{l}\text { COSTO } \\
(\mathrm{MO}) \\
(2)\end{array}$ & $\begin{array}{c}\text { PRECIO } \\
X \\
\text { UNIDAD } \\
\text { (3) }\end{array}$ & $\begin{array}{l}\text { PEDIDO } \\
\text { (3) X } 400 \\
\text { PIEZAS }\end{array}$ & $\begin{array}{l}\text { PORCENTAJE } \\
\text { EN COSTO } \\
(\mathrm{MO})\end{array}$ & $\begin{array}{l}\text { COSTO } \\
\text { FINAL } \\
(\mathrm{MO})\end{array}$ \\
\hline & & & & TIEMPO & $\%$ & (\$) & (\$) & FINAL & PRODUCTO & TOTAL \\
\hline 2004 & 6 & 5 & 1 & 15 días & $80 \%$ & $\$ 9.00$ & $\$ 15.00$ & $\$ 6,000$ & 60 & $\$ 3,600.00$ \\
\hline 2005 & 4 & 3 & 1 & 17 días & $60 \%$ & $\$ 9.00$ & $\$ 20.00$ & $\$ 8,000$ & 45 & $\$ 3,600.00$ \\
\hline 2006 & 4 & 2 & 2 & 30 días & $80 \%$ & $\$ 11.00$ & $\$ 20.00$ & $\$ 8,000$ & 55 & $\$ 4,400.00$ \\
\hline 2007 & 4 & 2 & 2 & 15 días & $50 \%$ & $\$ 8.00$ & $\$ 25.00$ & $\$ 10,000$ & 32 & $\$ 3,200.00$ \\
\hline 2008 & 4 & 2 & 2 & 45 días & $50 \%$ & $\$ 12.00$ & $\$ 100.00$ & $\$ 40,000$ & 12 & $\$ 4,800.00$ \\
\hline 2009 & 4 & 2 & 2 & 60 días & $50 \%$ & $\$ 40.00$ & $\$ 170.00$ & $\$ 68,000$ & 23.5 & $\$ 16,000.00$ \\
\hline \multicolumn{11}{|c|}{ Nota de términos simplificados; MO: Mano de obra. H (Hombre) M (Mujer). } \\
\hline \multicolumn{11}{|c|}{ Porcentaje en Costo $(\mathrm{MO})$ : Costo final $(\mathrm{MO})$ x 100 / Pedido final. } \\
\hline 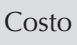 & Cret & & & 0 (piez & be & $=n$ & & & & \\
\hline
\end{tabular}

Fuente: Elaboración propia en base a los pedidos del taller, 2010.

Las tareas en los procesos artesanales deben hacer uso de las nuevas tecnologías en aquellas partes donde se requiera acelerar el proceso de manufactura (GIL, 2002: 39). En el cuadro 8, se detallan las tareas en el proceso de fabricación de artesanía dentro del taller analizado que tienen como objeto: el identificar la innovación efectuada dentro de la producción y diferenciar el aspecto operativo manual del realizado por la herramienta de trabajo. Demuestra la innovación y el cambio que el productor efectúa con el fin de obtener mayor productividad en la fabricación de sus artesanías. Un claro ejemplo es el empleo del Struder para el amasado del barro; 5 horas de diferencia que se pueden emplear en diversas tareas del taller. 


\begin{tabular}{|c|c|c|c|}
\hline \multicolumn{4}{|c|}{ CUADRO. 8 PROCESO PRODUCTIVO } \\
\hline TAREAS & FUNCIÓN & $\begin{array}{l}\text { APLICACIÓN EN } \\
\text { PROCESO }\end{array}$ & INNOVACIÓN EN PROCESO \\
\hline $\begin{array}{l}\text { Amasado de } \\
\text { pasta }\end{array}$ & MQ & Disminución en tiempo & $\begin{array}{l}\text { Empleo del Struder (amasado en } 1 \\
\text { hr contra } 6 \text { hrs Hombre) }\end{array}$ \\
\hline $\begin{array}{l}\text { Amasado de } \\
\text { pasta manual }\end{array}$ & $\mathrm{MO}$ & $\begin{array}{l}\text { Aplicación para elabo- } \\
\text { ración de producto }\end{array}$ & Mejoramiento práctico \\
\hline $\begin{array}{l}\text { Extensión de } \\
\text { pasta }\end{array}$ & $\mathrm{MO} / \mathrm{MQ}$ & $\begin{array}{l}\text { Estimado de extensión } \\
\text { de la pieza }\end{array}$ & Empleado con un rodillo \\
\hline $\begin{array}{l}\text { Uniformidad } \\
\text { de pasta }\end{array}$ & MQ & $\begin{array}{l}\text { Grosor específico de la } \\
\text { pieza }\end{array}$ & $\begin{array}{l}\text { Empleo de (tortilladora) uniformi- } \\
\text { dad exacta }\end{array}$ \\
\hline Recorte & $\mathrm{MO} / \mathrm{MQ}$ & $\begin{array}{l}\text { Adecuación de la figura } \\
\text { (forma) }\end{array}$ & $\begin{array}{l}\text { Aguja especial para cortes en } \\
\text { medidas estándar }\end{array}$ \\
\hline Placa & $\mathrm{MO} / \mathrm{MQ}$ & $\begin{array}{l}\text { Modelado y base para } \\
\text { secado uniforme }\end{array}$ & $\begin{array}{l}\text { Empleo torno eléctrico menor } \\
\text { tiempo modelado (hrs) }\end{array}$ \\
\hline Lijado & $\mathrm{MO}$ & Limpia de impurezas & Mejoramiento práctico \\
\hline $\begin{array}{l}\text { Esponjeo en } \\
\text { crudo }\end{array}$ & $\mathrm{MO}$ & $\begin{array}{l}\text { Limpia de impurezas y } \\
\text { estética al producto }\end{array}$ & Mejoramiento práctico \\
\hline $\begin{array}{l}\text { Sancocho } \\
\text { (quema del } \\
\text { producto) }\end{array}$ & MQ & $\begin{array}{l}\text { Primera cocción del } \\
\text { producto a } 1000{ }^{\circ} \mathrm{C}\end{array}$ & Menor tiempo igual a menor costo \\
\hline Plantilla & $\mathrm{MO}$ & $\begin{array}{l}\text { Diseño del logo y/o } \\
\text { marcas en caso de ser } \\
\text { requerido (forma ma- } \\
\text { nual) }\end{array}$ & Conocimiento en dibujo, pintura \\
\hline Decoración & $\mathrm{MO}$ & $\begin{array}{l}\text { Adhesión de formas, } \\
\text { colores, por el ingenio }\end{array}$ & $\begin{array}{l}\text { Conocimiento heredado desarrol- } \\
\text { lado en la práctica }\end{array}$ \\
\hline Engobe & $\mathrm{MO}$ & $\begin{array}{l}\text { Aplicación de aceite } \\
\text { para aislar el esmalte }\end{array}$ & $\begin{array}{l}\text { Conocimiento adquirido en la } \\
\text { práctica (permite mayor absor- } \\
\text { ción del esmalte) }\end{array}$ \\
\hline Esmalte & $\mathrm{MO}$ & $\begin{array}{l}\text { Aplicación manual in- } \\
\text { mersión en el esmalte } \\
\text { (sin plomo) }\end{array}$ & $\begin{array}{l}\text { Aplicación (cambio al permitir la } \\
\text { libre comercialización de los pro- } \\
\text { ductos sin daños a la salud) }\end{array}$ \\
\hline Esponjeo & $\mathrm{MO}$ & $\begin{array}{l}\text { Limpieza final para } \\
\text { limpia externa }\end{array}$ & \\
\hline Horneado & MQ & $\begin{array}{l}\text { Horneado final } 1100^{\circ} \mathrm{C} \\
\text { (cocción) }\end{array}$ & $\begin{array}{l}\text { Menor tiempo en quema del pro- } \\
\text { ducto - menor costo - menor } \\
\text { merma / empleo de medidor de } \\
\text { temperatura }\end{array}$ \\
\hline
\end{tabular}

Fuente: Elaboración propia con base en el proceso artesanal y datos del artesano. 
La maquinaria que cuenta el taller es muestra del grado de innovación con la que la empresa está familiarizada. Los avances en construcción de hornos, la tortilladora (base para piezas), recorte de la moldura de la pieza, el torno eléctrico, así como el mejoramiento de los procesos de fabricación, son muestra de la tendencia de la empresa a desarrollar acciones deliberadas de aprendizaje tecnológico. Está en contacto con asesoría de nuevos procesos y productos con una universidad privada, con el fin de conocer nueva información sobre materiales y mejoras en algunos procesos. El artesano está en constante capacitación, estudió un curso de taller sobre técnicas nuevas enfocado a cerámica, innovación en colores y formas, en el 2007. Para disponer de recursos financieros, la empresa lo concibe como significativo. El taller optó en el 2008 por aumentar la maquinaria por la vía de un crédito en Fondo Jalisco (FOJAL), éste se empleó en la mejora de la capacidad instalada del taller (cuadro 9).

\begin{tabular}{|c|c|c|}
\hline \multicolumn{3}{|c|}{ CUADRO 9 INVERSIÓN EN MAQUINARIA } \\
\hline $\begin{array}{l}\text { AÑO DE } \\
\text { COMPRA }\end{array}$ & & RECURSOS FINANCIEROS \\
\hline 2004 & $\begin{array}{l}\text { - Torno pedal artesanal } \\
\text { - Horno superficie }\left(0.5 \mathrm{~m}^{2}\right) \text { capacidad de } \\
\text { producción } 30 \text { piezas (chicas } 15 \mathrm{~cm}) \\
\text { - Temperatura baja }\end{array}$ & $\begin{array}{l}\text { - Recursos propios ingreso } \\
\text { de pedidos }\end{array}$ \\
\hline 2005 & $\begin{array}{l}\text { - Prensa mecánica para plato (Desarrollo } \\
\text { de relieve en las piezas) }\end{array}$ & $\begin{array}{l}\text { - Recursos propios ingreso } \\
\text { de pedidos }\end{array}$ \\
\hline 2008 & $\begin{array}{l}\text { - Adecuación de horno a mayor capacidad } \\
\left(1 \mathrm{~m}^{2}\right) \text { producción } 50 \text { piezas (chicas } 15 \mathrm{~cm} \text { ) } \\
\text { - Torno de yeso para modelar } \\
\text { - Burro de secado (Anaquel) }\end{array}$ & $\begin{array}{l}\text { - Crédito FOJAL } \\
\text { Lapso } 24 \text { meses }\end{array}$ \\
\hline 2009 & $\begin{array}{l}\text { - Struder (amasadora) } \\
1 \text { costal } 30 \text { Kg en } 2 \text { horas/ } 8 \text { costales } \\
\text { - Tarraja (formación de piezas redondas) } \\
\text { - Tortilladora (sacar la base de la pieza) } \\
\text { - Afinadora } \\
\text { (esponjeo de la pieza para sancocho) } \\
\text { - Burro secado (anaquel) } \\
\text { evitar que la corriente de aire toque la pieza } \\
\text { - Ampliación horno superficie ( } 1.3 \mathrm{~m}^{2} \text { ) } \\
100 \text { piezas (chicas } 15 \mathrm{~cm} \text { ) } \\
\text { - Horno (2.6 m²) } \\
200 \text { piezas (chicas } 15 \mathrm{~cm} \text { ) }\end{array}$ & $\begin{array}{l}\text { - Recursos propios ingreso } \\
\text { de pedidos }\end{array}$ \\
\hline
\end{tabular}

Fuente: Elaboración propia con base en los datos del artesano, 2010. 
A diferencia de optar por una opción crediticia con el fin de compra de materiales, la empresa lo destinó a un mejoramiento para la producción, el mayor incremento de maquinaria se asocia con el incremento de producción.

El cliente final es el principal canal con el que ha obtenido ventas el taller, se brinda el producto y servicio requerido en forma directa, sin embargo, es claro que el alto ingreso proviene de los intermediarios. Como política de pagos para los clientes ha establecido el cincuenta por ciento al realizar el pedido, y el cincuenta restante al entregarlo en el taller. El modelo poco reactivo de estimar la demanda ha hecho que en ocasiones el artesano no cuente con productos, lo cual disminuye sus ventas.

El taller se enfocó en identificar las diferencias en las necesidades de los compradores nacionales y mantuvo el mercado cautivo de clientes locales, así como la experimentación con compradores extranjeros o con turistas. El Cuadro 10, muestra que al inicio de operaciones, el taller se enfocó en los intermediarios, lo que aumentó su capacidad de producción; el problema fue la dependencia hacia el comprador, cuando el cliente buscó otras opciones, el artesano careció de canales para mantener sus ingresos, al ser dependiente de la promoción del intermediario y no le permitía expandir su mercado.

\begin{tabular}{|c|c|c|c|c|c|c|c|}
\hline \multirow{2}{*}{$\frac{\mathrm{CU}}{\mathrm{ADO}}$} & \multicolumn{7}{|c|}{ AÑOS EN OPERACIONES } \\
\hline & & 2004 & 2005 & 2006 & 2007 & 2008 & 2009 \\
\hline Consumidor final & Local & $10 \%$ & $10 \%$ & $25 \%$ & $30 \%$ & $30 \%$ & $60 \%$ \\
\hline \multirow[t]{4}{*}{ Intermediario } & Local & $55 \%$ & $75 \%$ & $60 \%$ & $65 \%$ & $55 \%$ & $25 \%$ \\
\hline & Regional & $10 \%$ & $10 \%$ & $5 \%$ & $0 \%$ & $10 \%$ & $10 \%$ \\
\hline & Nacional & $0 \%$ & $0 \%$ & $0 \%$ & $0 \%$ & $0 \%$ & $0 \%$ \\
\hline & Internacional & $0 \%$ & $0 \%$ & $0 \%$ & $0 \%$ & $0 \%$ & $0 \%$ \\
\hline \multirow[t]{3}{*}{ Exposiciones } & Local & $5 \%$ & $4 \%$ & $5 \%$ & $2 \%$ & $0 \%$ & $0 \%$ \\
\hline & Nacional & $0 \%$ & $1 \%$ & $2 \%$ & $3 \%$ & $4 \%$ & $5 \%$ \\
\hline & Extranjera & $0 \%$ & $0 \%$ & $0 \%$ & $0 \%$ & $1 \%$ & $0 \%$ \\
\hline Tiendas & Regional & $20 \%$ & $0 \%$ & $3 \%$ & $0 \%$ & $0 \%$ & $0 \%$ \\
\hline
\end{tabular}

Fuente: Elaboración propia en base a información del artesano, 2010.

Las fuentes importantes de influencia en el desarrollo del taller y el ambiente percibido, de acuerdo a las entrevistas realizadas al dueño y la observación participante se encontró que existe:

- Nulo desarrollo de un canal de ventas, la dependencia de los intermediarios;

- Deficientes herramientas en los cálculos de precios e información de mercados; 
- El apoyo del gobierno en capacitación y préstamos no es prioritario en el taller;

- Flexibilidad para adaptar e innovar líneas de productos;

- Promoción en ferias nacionales e internacionales sin captación de clientes;

- Prevalece la deficiencia en: conocimiento de la competencia en nuevos productos, diversificación en precios, búsqueda y asociación de mercado.

El estudio hecho por Cota y López (2007) sobre talleres grandes de artesanía en Tonalá determina el nivel de innovación con el que el taller se enfrenta hacia el mercado. El aspecto generador de rentas al interior de las empresas analizadas es el fortalecimiento de los procesos de producción por medio de la tecnología diseñada, a su vez, la mano de obra con la que cuentan que permite lograr una productividad por la especialización del personal (Cuadro 11). El cuadro presenta las conclusiones con respecto a las decisiones que toma el taller del caso de estudio, en el comparativo con los talleres que permite analizar tanto ventajas, debilidades y oportunidades en el mercado de artesanía. 


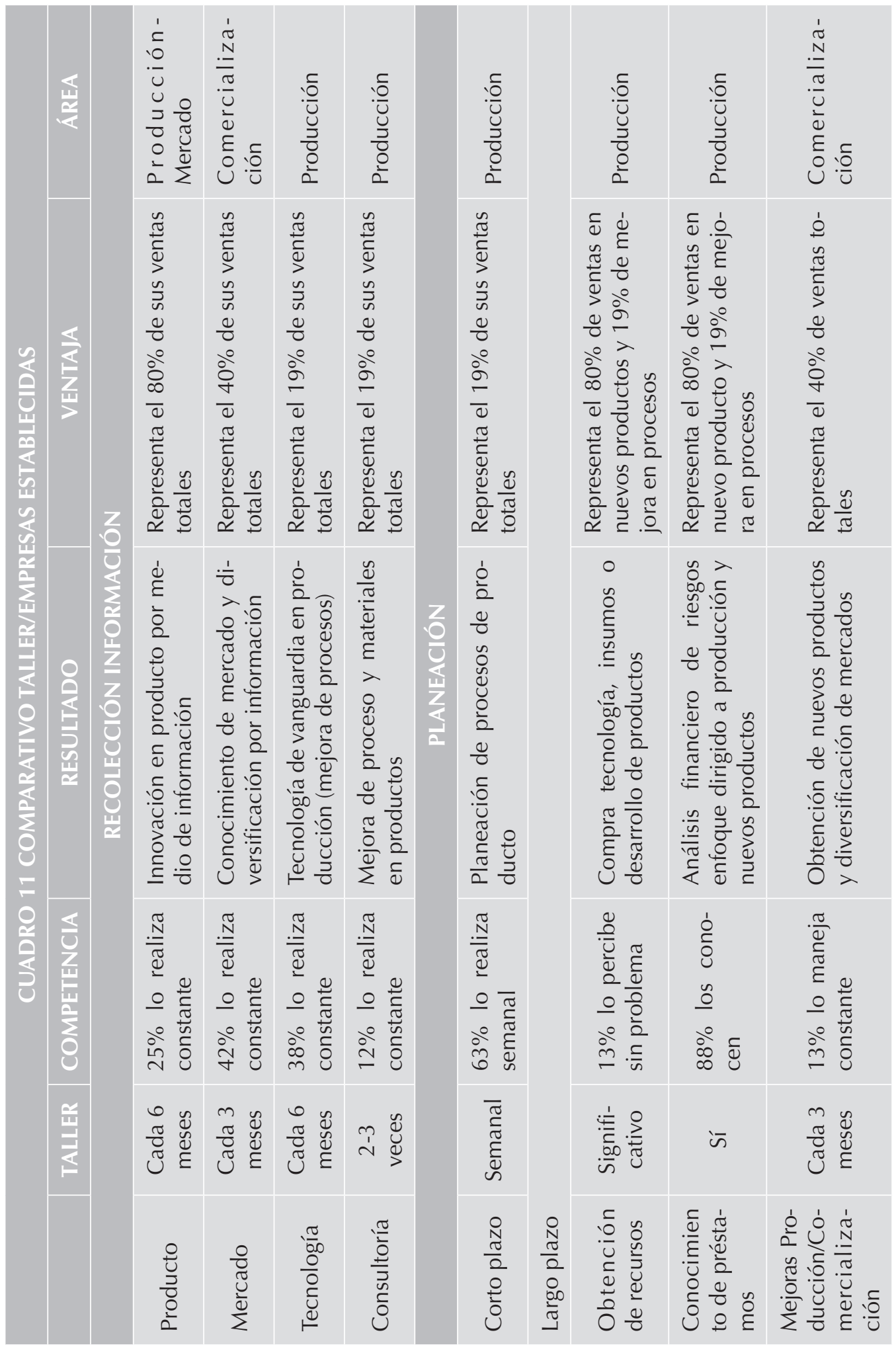



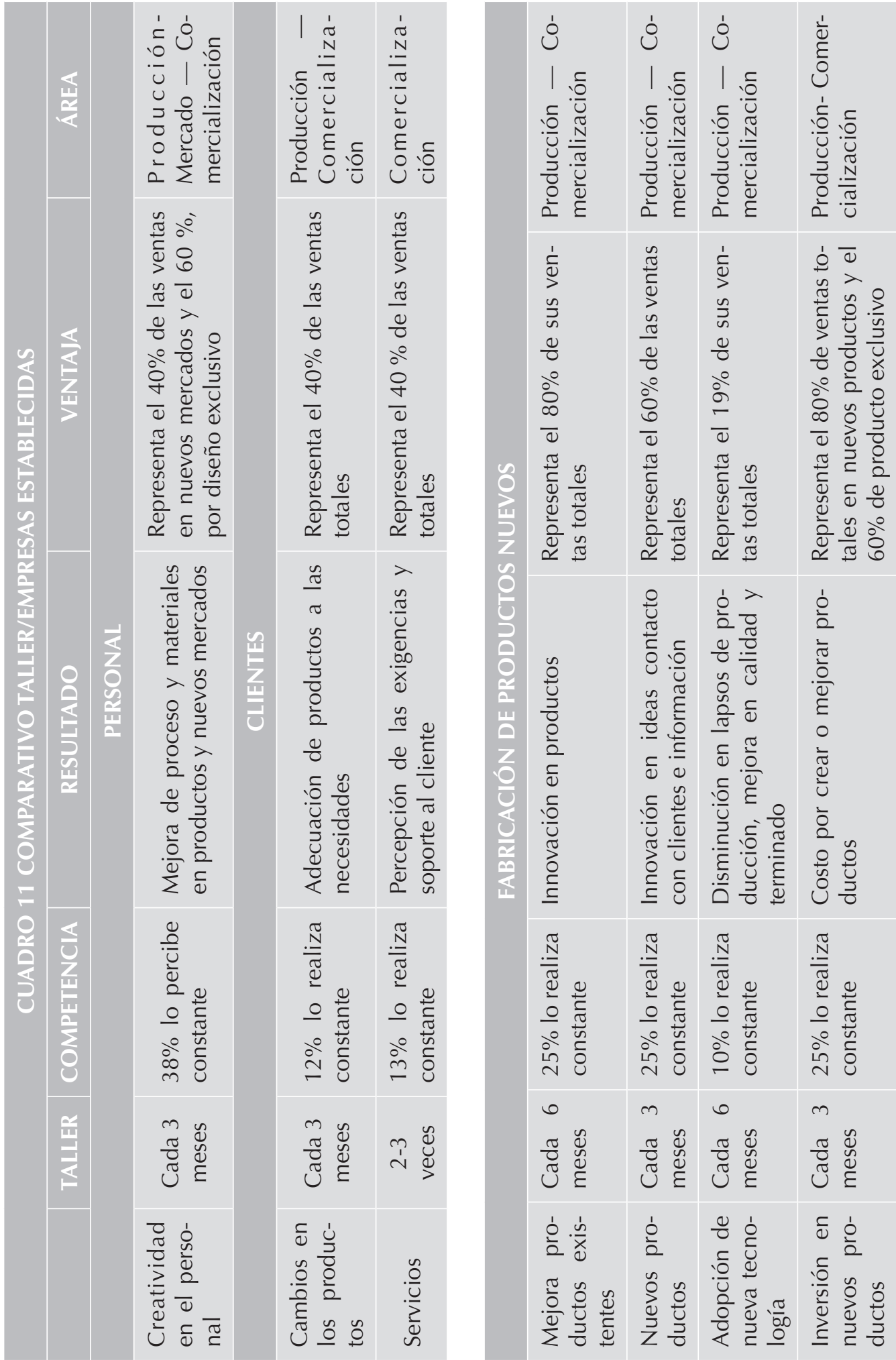


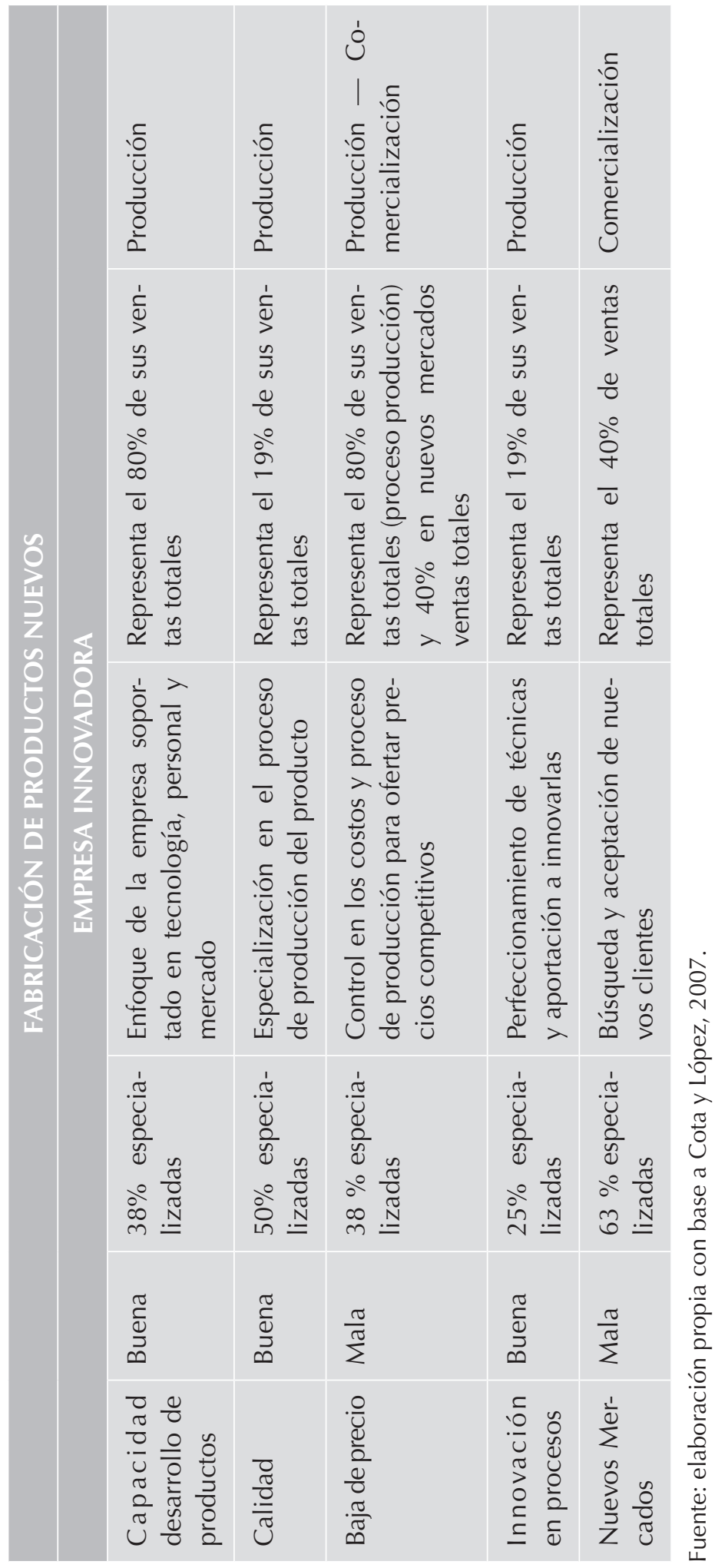




\section{CONCLUSiOnes}

La apertura comercial de México ha traído ventajas económicas para algunas empresas, lo que propicia la participación de varios productos en los mercados globales. Mediante el presente estudio se ha logrado identificar una óptica competitiva de la actividad artesanal, a saber, en los talleres persisten las carencias en la organización para comercializar, y las dificultades inmersas que conducen el plantear negocios de exportación.

Esto se debe principalmente a la competencia y al constante cambio en el sector de decoración que, al no permitir a las empresas mantenerse inactivas, se ha vuelto agresivo en cuanto a precios, tiempos de entrega, volúmenes, a la par los cambios en la perspectiva del consumidor; la más significativa: el trabajo artesanal se devalúa al no concebir el valor cultural intrínseco en las mercancías; el consumidor exige un mayor valor de uso en los productos.

Dentro de las zonas económicas artesanales se eligió Tonalá dado las ventajas competitivas que cuenta: proximidad al mercado: una zona turística importante donde convergen compradores; proximidad a los proveedores de insumos; conexiones a las carreteras federales, así como con la disponibilidad de empresas transportistas de carga; servicios públicos y privados idóneos; condiciones climáticas favorables; la mano de obra es especializada, debido a la tradición cultural arraigada y la flexibilidad en la transmisión de conocimiento en las familias.

Las más claras deficiencias para la exportación de los talleres artesanales son: falta de información sobre competencia y búsqueda de nuevos mercados; el cálculo de costos de producción, de precios de venta, así como la labor de promoción del producto; y el capital financiero, para sostener operaciones.

En contra parte las ventajas en la fabricación son las prácticas de manufactura empleadas que permiten la libre comercialización del producto a nivel internacional: el horneo de los productos al utilizar horno de gas y el empleo de materiales para la decoración libres de plomo aptos para el consumo humano. Como sugerencia para los talleres algunas estrategias importantes para el ingreso al comercio internacional son: exposiciones culturales, unión con otros productores artesanos, participación en programas de apoyo del gobierno, implementación de tecnología (tecnificación). Certificados de calidad (determinación de origen). Recursos intangibles: la marca y el valor asociado como factor de confianza. Retroalimentación con los clientes (usuarios o compradores).

\section{Bibliografía}

Comercio Exterior por producto; SIAVI; Fracción arancelaria; 69139099 en Secretaria de Economía http://www.economia.gob.mx/?P=5400. Fecha de consulta: 8 de julio 2011.

Comercio Exterior de Jalisco. Clasificación por ramas económicas (2010). Disponible en: http://sin. jalisco.gob.mx/cognos8/cgi-bin/cognos.cgi. Fecha de consulta: 8 de julio 2011.

Correa Miranda, Olga; Correa Pérez, Genaro; Carmona Mares, Rosaura (2009). Los tipos de espacios de la economía artesanal-turística en México. Posgrado en Geografía. UNAM. México. 
COTA YÁÑEZ, Rosario y LÓPEZ, Carlos Alberto (2007). La presencia de innovación como factor estratégico de competitividad: El caso de las empresas que producen artesanías en Tonalá, Jalisco. Carta Económica Regional. Universidad de Guadalajara, Guadalajara, p. 18-32.

COWEN, Tyler y PARKER, David (1998). Los mercados en las empresas: un enfoque gerencial. Revista Libertas 28 (Mayo 1998), Instituto Universitario ESEADE.

CUEVAS HERNÁNDEZ, Ana Josefina (2007). Turismo y consumo artesanal en Tlaquepaque, Jalisco, México, en tres etapas del siglo XX. Estudios sobre las culturas contemporáneas, diciembre, Época II, año v. XIII, n. 026, Universidad de Colima, Colima México, p. 103-125.

DE BUEN LOZANO, Néstor (1997). El trabajo antes de la Revolución Industrial. Instituciones de derecho del trabajo y de la seguridad social. Estudios Doctrinales, n. 188.

FUJITA, Masahisa e KRUGMAN, Paul (2004). La nueva geografía económica: pasado, presente y futuro. Investigaciones Regionales, n. 4. Asociación Española Ciencia Regional, p. 177-206.

GIL TEJEDA, Jorge (2002). Consejo Nacional de Ciencia y Tecnología. El nuevo diseño artesanal. Análisis y prospectiva en México. Febrero, Barcelona, Tesis de Doctoral.

GONZÁLEZ PACHECO, León, ALEJANDRA y DUSSEL PETERS, Enrique (2001). El comercio intraindustrial en México, 1990-1999. Comercio Exterior, v. 51, n. 7, México, Julio.

HERNÁNDEZ GIRÓN, José de la Paz; DOMÍNGUEZ HERNÁNDEZ, María Luisa e RAMOS SÁNCHEZ, Arelí Orquídea (2002). Canales de distribución y competitividad en artesanías. Espiral. Universidad de Guadalajara, Guadalajara, v. 9; n. 25. p. 143-164.

HERNÁNDEZ GIRÓN, José de la Paz; YESCA LEÓN, María e DOMÍNGUEZ HERNÁNDEZ, María Luisa (2007). Factores de éxito en los negocios de artesanía en México. Estudios gerenciales, Jul.-Sep, v. 23, n. 104. p. 77-99.

LÓPEZ ARÉVALO, Jorge Alberto e RODIL MARZÁBAL, Óscar (2008). Comercio intraindustrial e intrafirma en México en el contexto del proceso de integración de América del Norte (1993-2006). Economía UNAM, n. 013, Enero.

LUGO-MORIN DIOSEY, Ramón; RAMÍREZ JUÁREZ, Javier; NAVARRO GARZA, Hermilio e ESTRELLA CHULÍM, Néstor (2008). Etnocompetitividad del sistema artesanal textil Mitla, el papel del territorio y la innovación. Economía, sociedad y territorio, v. 8, n. 28, p. 981-1006.

MARTÍNEZ CARAZO, Piedad Cristina (2006). El método de estudio de caso: Estrategia Metodológica de la investigación científica. Pensamiento \& Gestión, Julio, 2006, n. 20.

MENDOZA COTA, Jorge Eduardo; PÉREZ CRUZ, Jorge Alberto. Aglomeración, encadenamientos industriales y cambios en la localización manufacturera en México. Economía, Sociedady Territorio, v. n. 23, p. 655-691, 2007.

MOCTEZUMA YANO, Patricia. Artesanas y artesanos frente a la globalización. v. 24, n. 93 . El Colegio de Michoacán, Zamora, de México, p. 270-277, 2002.

NOVELO OPPENHEIM, Victoria (2008). La fuerza de trabajo artesanal mexicana, protagonista ipermanente? de la industria Alteridades, v. 18, n. 35, p. 117-126, enero-junio, 2008.

PALERM VIQUEIRA, Ángel e MORENO VILLANUEVA, Lissette Wendy. Comercio intraindustrial en el sector manufacturero mexicano. Comercio Exterior, v. 51, n. 9, p. 789-794, 2001.

PORTER, Michael E. (1990). The competitive advantage of nations. Harvard Business Review, p. 72-91, March-April.

RODRÍGUEZ MIRANDA, Adrián. Desarrollo económico territorial endógeno: Teoría y aplicación al caso Uruguayo. Junio, Instituto de Economía, Uruguay, 2006. 
SALAS ALFARO, Renato e PÉREZ MORALES, S. Mario (2007). Transformaciones socioeconómicas en la unidad domestica campesina de San Miguel, Oaxaca. Economía y Sociedad, v. XII, n. 20, p. 223-243, Jul-Dic.

TUROK, Martha. Como acercarse a la artesanía. Plaza y Valdés. México, 1988.

VÁZQUEZ -BARQUERO, Antonio. Desarrollo endógeno y globalización. Eure Dic. v. XXVI, n. 79. Pontifica Universidad Católica de Chile; Santiago, Chile, 2000.

WERNERFELT, Birger. A Resource-Based View of the Firm. Strategic Management Journal, v. 5, n. 2, p. 171-180, Apr.-Jun., 1984. 